\title{
Sensory recovery in the plantar aspect of the foot after surgical decompression of posterior tibial nerve. Possible role of steroids along with decompression
}

\author{
K S RAO \& M K SIDDALINGA SWAMY \\ Department of Orthopaedic and Reconstructive Surgery, Central \\ Leprosy Teaching and Research Institute, Chengalpattu PIN-603 \\ 001, India
}

\section{Accepted for publication 7 April 1989}

\begin{abstract}
Summary In leprosy, involvement of the posterior tibial nerve leads to sensory loss in the plantar aspect of the foot. As a result plantar ulcers are common and lead to deformity and disability. Restoration of plantar sensation can prevent ulcer formation.

Posterior tibial decompression was done for the recovery of sensation in the plantar aspect of the foot. Seventy-two patients under went decompression on 84 feet, 25 received steroids pre- and post-operatively. The recovery of sensation was better if surgery was done before 6 months of onset of anaesthesia. Decompression along with steroids gave better results than decompression alone in patients with active neuritis especially in BT cases whereas in BB, BL and LL cases there was no significant improvement of sensation. The results are discussed.
\end{abstract}

\section{Introduction}

Involvement of the posterior tibial nerve is common in leprosy and leads to loss of sensation in the plantar aspect and paralysis of the small muscles of the foot. Plantar ulcers are an unfortunate problem due to anaesthesia of the feet. If sensory function is restored to the foot it is possible to prevent ulcers and late complications.

Various studies ${ }^{1,2,4,6}$ have reported recovery of sensation and motor function after decompression of the ulnar nerve. An analysis of the recovery of sensation af ter PT decompression was done at CLT \& RI, Chengalpattu. Initially PT decompression was done for painful neuritis and patients were on steroid therapy as well. Because there was a good recovery of sensation after surgery, patients with plantar anaesthesia but without neuritis were also considered for surgery although they were not given steroids. The results were analysed for recovery of plantar sensation after PT decompression with and without steroids. Steroids help in suppressing the immunological response in the nerve and relieve the tension by decreasing the oedema and inflammation. Surgical decompression relieves external and internal compression of the nerve. 


\section{Materials and methods}

The study was done at the Central Leprosy Teaching and Research Institute, Chengalpattu to find the effect of posterior tibial decompression on recovery of sensation. The study was carried out from November 1982 to December 1986. The type of disease according to the Ridley-Jopling scale, treatment, bacteriological status and duration of anaesthesia were recorded. Due importance was given to the cases with anaesthesia of short duration and some patients who had painful neuritis were given steroids as well as surgery. The dosage of steroids varied from 60 to $20 \mathrm{mg}$ and was given for 3-4 months.

Touch, pain, pressure and vibration were tested over the plantar aspect of the foot. Touch was tested with No. 5 Nylon, pain with a pinprick, pressure with the blunt end of a pin and vibration with a tuning-fork. Thermal and two-point discrimination were not tested as there was difficulty in testing them in the plantar area. The foot was divided into six areas, namely; big toes, lateral and medial aspect of forefoot, instep and outerside of midfoot, and heel. Each area was tested for sensation, touch, pain and pressure. Vibration sensation was tested over the head of the 1st MTH, 5th MTH and heel for both high and low frequency. Motor deficit was not considered as it was difficult to assess the same without EMG.

Assessment was done by giving a score. For presence of each type of modality of sensation in one area one mark was given. A total of six areas were tested for 4 modalities the maximum total score being 24. If touch, pain, pressure and vibration were absent in 3 areas, the score would be 12 ( 24 minus 12). Post-operatively if there were recovery of all sensation in 2 areas the score would be 20 . The percentage of recovery was $50 \%$ compared to the loss, i.e. 6 points out of 12 . The results were grouped into five categories:

Excellent, recovery of $76 \%$,

Good, recovery of $51-75 \%$,

Fair, recovery of $26-50 \%$,

Poor, no recovery or less than $25 \%$ recovery,

Loss, deterioration of intact sensation in partial anaesthesia.

According to the area of recovery, it was grouped into four. Recovery in heel, midfoot, foref oot and toes. PT decompression with steroids and without steroids were analysed. Duration of loss of sensation was another important factor in assessing the results.

Posterior tibial decompression was done using standard incision. The nerve and its branches, namely calcaneal, medial and lateral plantar were identified and traced to the plantar aspect. Epifascicular epineurotomy was done. Intrafascicular decompression was not done. The posterior tibial vessels were identified and traced upwards and downwards. A part of the flexor retinaculum was excised. Those who had steroids pre-operatively continued to have steroids post-operatively.

Post-operative assessment was done 4 weeks after surgery and repeated every 3 months in the 1 st year and every 6 months in the next year and later yearly assessment was carried out. The patients were advised about their feet and MCR footwear was given to all patients.

\section{Observation and analysis}

During the period from November 1982 to December 1986, 94 posterior tibial decompressions were done for sensory loss in the plantar aspect of the foot. Twelve patients underwent bilateral decompression. There were 68 males and 4 females. The age of the patients varied from 14 to 57 years with an average of 28.6 years. In 42 cases decompression was done on the right side, 30 on the left side and bilaterally on 12 cases. There was thickening of the posterior tibial nerve in all patients, tenderness over the nerve in 34 cases and a history of recurrent neuritis in 21 cases. The posterior tibial pulsations were well felt in 77 limbs and were feeble in seven. The duration of anaesthesia in 
Table 1. Duration of anaesthesia before surgery

\begin{tabular}{lccc}
\hline Period & $\begin{array}{c}\text { No. of cases } \\
\text { in steroid } \\
\text { group }\end{array}$ & $\begin{array}{c}\text { No. of cases } \\
\text { in no steroid } \\
\text { group }\end{array}$ & Total \\
\hline$<6$ months & 12 & 23 & 35 \\
$6-12$ months & 7 & 9 & 16 \\
$1-2$ years & 4 & 7 & 11 \\
$>-2$ years & 2 & 20 & 22 \\
\hline Total & 25 & 59 & 84 \\
\hline
\end{tabular}

the plantar aspect of the foot varied from 1 month to 15 years. In 25 cases steroids were given along with decompression of the nerve and in 59 cases only decompression was done. The type of leprosy was classified according to Ridley-Jopling T-1, BT-35, BB-14, BL-07, LL-15. All the patients were on chemotherapy before surgery. Thirteen patients received MDT and 59 received monotherapy (DDS). The period of treatment varied from 6 months to 20 years. Most of the patients had developed anaesthesia in their feet during treatment, most probably due to reactions. Twenty-two patients were bacteriologically positive and 50 were negative. The follow-up period varied from 1.5 years to $5 \cdot 5$ years.

Loss of sensation varied from complete anaesthesia to loss of one modality in a few areas. Postoperatively sensation was tested in the ward. Patients reported some subjective improvement but no recovery was found. Fourth week post-operative assessment showed recovery of sensation which continued to improve for up to 6 months af ter which not much recovery was found. Recovery of sensation stayed constant without deterioration in cases where there was improvement.

The results were graded into 5 groups as discussed in Materials and methods. The results are given in Tables 2 and 3, depending upon whether they received steroids or not.

The recovery of sensation in different areas of the foot was as follows:

$$
\begin{aligned}
& \text { Toes, 53.03\% (35/66) } \\
& \text { Forefoot, } 70 \cdot 14 \%(47 / 67) \\
& \text { Midfoot, } 68 \cdot 91 \%(51 / 74) \\
& \text { Heel, } 54 \cdot 68 \%(35 / 64)
\end{aligned}
$$

Complete recovery of sensation was found in 15 out of 84 cases $(17 \cdot 85 \%)$.

Table 2. Recovery/duration of anaesthesia with PT decompression alone

\begin{tabular}{lccccc}
\hline & \multicolumn{5}{c}{ Duration of anaesthesia } \\
\cline { 2 - 5 } Result & $<6 \mathrm{~m}$ & $6-12 \mathrm{~m}$ & $1-2 \mathrm{yr}$ & $>2 \mathrm{yr}$ & Total \% \\
\hline Excellent & 9 & 5 & 1 & 3 & $18(30 \cdot 5)$ \\
Good & 5 & 2 & 3 & 3 & $13(22 \cdot 03)$ \\
Fair & 5 & 1 & 0 & 1 & $7(11 \cdot 86)$ \\
Poor & 2 & 1 & 3 & 9 & $15(25 \cdot 02)$ \\
Loss & 2 & 0 & 0 & 4 & $6(10 \cdot 16)$ \\
\hline Total & 23 & 9 & 7 & 20 & $59-$ \\
\hline
\end{tabular}


Table 3. Recovery/duration of anaesthesia after decompression along with steroids

\begin{tabular}{lrrrrr}
\hline & \multicolumn{4}{c}{ Duration of anaesthesia } & \\
\cline { 2 - 5 } Result & $<6 \mathrm{~m}$ & $6-12 \mathrm{~m}$ & $1-2 \mathrm{yr}$ & $>2 \mathrm{yr}$ & Total $(\%)$ \\
\hline Excellent & 10 & 0 & 2 & 1 & $13(52)$ \\
Good & 0 & 4 & 1 & 0 & $5(20)$ \\
Fair & 2 & 2 & 1 & 1 & $6(24)$ \\
Poor & 0 & 0 & 0 & 0 & $0(0)$ \\
Loss & 0 & 1 & 0 & 0 & $1(4)$ \\
\hline Total & 12 & 7 & 4 & 2 & $25-$ \\
\hline
\end{tabular}

Table 4. Type of leprosy and recovery of sensation

\begin{tabular}{|c|c|c|c|c|c|c|c|c|c|c|c|c|}
\hline \multirow{2}{*}{$\begin{array}{l}\text { Type } \\
\text { of } \\
\text { leprosy }\end{array}$} & \multicolumn{6}{|c|}{$\begin{array}{l}\text { Patients without steroids } \\
\text { (No. of feet) }\end{array}$} & \multicolumn{6}{|c|}{$\begin{array}{l}\text { Patients with steroids } \\
\text { (No. of feet) }\end{array}$} \\
\hline & Exce. & Good & Fair & Poor & Loss & Total & Exce. & Good & Fair & Poor & Loss & Total \\
\hline $\mathrm{T}$ & - & 1 & - & - & - & 1 & - & - & - & - & - & 0 \\
\hline BT & 11 & 2 & 1 & 8 & 4 & 26 & 9 & 2 & 2 & - & - & 13 \\
\hline BB & 2 & 5 & 3 & 2 & - & 12 & 2 & 1 & 3 & - & - & 6 \\
\hline BL & 1 & 3 & 1 & 2 & 2 & 9 & - & - & - & - & - & 0 \\
\hline LL & 4 & 2 & 2 & 3 & - & 11 & 2 & 2 & 1 & 0 & 1 & 6 \\
\hline Total & 18 & 13 & 7 & 15 & 6 & 59 & 13 & 5 & 6 & 0 & 1 & 25 \\
\hline
\end{tabular}

Type of leprosy and recovery of sensation is given in Table 4 .

Although it is not possible to compare the type of leprosy and recovery of sensation, it is found that in cases of BT leprosy decompression with steroids gave better results than decompression alone. In other types of leprosy the recovery of sensation was not very significant whether patients received steroids or not.

\section{Discussion}

Restoration of sensation in the plantar aspect of the foot plays a major role in prevention of the most troublesome problem in leprosy, namely plantar ulcers, which lead to mutilation, absorption, and amputation, so that the rehabilitative measures which are difficult are avoided.

Eighty-four feet underwent decompression of the posterior tibial nerve, in which there was complete recovery of sensation in $15(17 \cdot 8 \%)$. The results were satisfactory which include excellent, and good results in $49(58 \%)$. There was minimal or no recovery in $15(17.8 \%)$ and deterioration of sensation in partial anaesthetic feet was found in $7(8 \cdot 3 \%)$.

Recovery of sensation was better in cases where decompression was done within 6 months of onset of anaesthesia. Satisfactory results (excellent and good) were found in 24 out of $35(68 \%)$ who had anaesthesia of less than 6 months duration.

Comparing the results of PT decompression with and without steroids, it was found that 
steroids with PT decompression gave better results $(P<0 \cdot 05)$. Satisfactory (excellent and good) results were found in 31 out of 59 where steroids were not given $(52.4 \%)$ whereas with steroids satisfactory results were found in 18 out of $25(72 \%)$. The results of steroid and non-steroid groups were quite significant in BT cases. Thirteen out of 26 cases in the non-steroid group had satisfactory whereas in the steroid group, 11 out of 13 cases had satisfactory results.

Even in the patients where steroids were used, the results were better if the duration of anaesthesia was less than 6 months $(P<0 \cdot 01)$. The recovery was satisfactory (excellent and good) in 10 out of 12 cases $(83.33 \%)$ with steroids, whereas in patients not given steroids satisfactory result were found in 14 out of $23(60 \%)$. Regarding the type of leprosy and recovery of sensation, it was found that in the 'BT' type of leprosy, decompression with steroids gave better results than decompression alone. The pattern of recovery was similar in BB, BL and LL cases whether they received steroids or not. Out of 32 cases who had decompression alone there was satisfactory recovery in 17 cases and satisfactory results were found in 7 cases out of 12 who received steroids along with decompression. Therefore there was no significant improvement of sensation with the addition of steroids.

Deterioration of anaesthesia after surgery was found in cases where the anaesthesia was of a longer duration and without steroids.

In anaesthesia of a shorter duration in the plantar aspect of the foot, decompression of the posterior tibial nerve along with steroids gives a better chance for the recovery of sensation. Decompression is both external and internal. External decompression as the tough flexor retinaculum was incised and later, as a part of it was excised. Internal decompression was done by epineurotomy. It is not possible to say how much internal decompression is done by epineurotomy. Internal neurolysis was not done as it may damage the nerve rather than help recovery.

Corticosteroids have a definite role in helping recovery by suppressing the immunological response within the nerve. Internal compression is also relieved to a great extent as the inflammatory oedema subsides with steroids. Addition of steroids together with decompression makes a significant contribution to the recovery of sensation in BT cases. To evaluate the significant role of steroids in recovery of sensation a controlled study is essential, keeping all the parameters constant.

\section{Acknowledgments}

We are thankful to the Director, Central Leprosy Teaching and Research Institute, Chengalpattu and the Director General, ICMR for their permission to publish this paper. Financial assistance was given by ICMR for this study. We also thank Mr Anand, Mrs Thenmozhi, Physiotherapists, Smt Nalinakshi, Research Assistant and Miss N Suguna, Stenographer for their help. We are very grateful to Dr H Srinivasan, Senior Orthopaedic Surgeon, CLT \& RI, Chengalpattu, at present Director, JALMA Institute, Agra who initiated and guided the project.

\section{References}

1 Anita NH, Vankani B, Pandya NJ. Decompression of ulnar nerve in leprosy neuritis. Lepr India, 1976; 48: $262-370$.

2 Thomas AA, Selva Pandyan AJ, Sam AS, Joseph D, Chellan DD. Comparative study of surgical decompression by medial epicondlylectomy and medial decompression by steroids for management of ulnar neuritis and early paralysis. Lepr India, 1979; 54: 287-302.

${ }^{3}$ Parikh AC, Ganapati R, Kothare KB, Divekar SC. Decompression of ulnar and median nerves in leprous neuritis. Lepr Rev, 1968; 39: 143-6.

${ }^{4}$ Palande DD. Surgery of ulnar nerve in leprosy. Lepr India, 1980; 52: 74-88.

5 Ranade SS, Gokhale BB, Momim G. Epineurotomy in the treatment of trophic ulcers in leprosy. Lepr India, 1957; 29: 48-51.

6 Vidayanathan EP, Vidayanathan SA. Treatment of ulnar neuritis and early ulnar paralysis. Lepr Rev, 1968; 39: $217-22$. 